\title{
If the Only Tool You Have Is a Hammer, You Will Treat Everything as a Nail: Exploring Why Construction Contractors Monetise Social Value
}

\author{
Greg Watts \\ University of Salford \\ Anthony Higham \\ University of Salford
}

The need to measure and communicate Social Value (SV) is now a priority for many construction contractors. However, this can prove difficult as there exists a conflict at the heart of $S V$ between its subjective nature and the objective way $S V$ is often measured. It needs to be ascertained exactly how contractors measure $S V$ and why, and if monetary metrics are increasingly used for $S V$ measurement, what are the ramifications. This paper aims to understand the motivations and ramifications of contractor $S V$ measurement behaviour, as well as the implications for industry leadership and management.

Keywords: Maslow, social value, corporate social responsibility, legitimacy theory

\section{INTRODUCTION}

The estimated annual revenue of the global construction industry is set to be $\$ 15$ trillion by 2025 (Deloitte, 2019). The same report reveals that with global economies set to increase between 2.5\% and 3\% annually over the next few years, the pace of construction growth is set to exceed this with average growth of $3.6 \%$. This underlines the importance of the construction industry on a global scale and so arguably any increased positive impacts the industry can achieve will reverberate with increased positive ramifications for all stakeholders involved. These stakeholders include both those directly and indirectly impacted by the construction works as well as the entire life cycle of the building, and are often diverse, with different cultural backgrounds, and include individuals and groups temporarily and permanently impacted due to the nature of construction works (Xue et al., 2020). This potential for increased positive stakeholder impact has in recent years been accompanied by an increased stakeholder demand that companies should create additional Social Value (SV) where possible and ensure they provide a positive contribution to society. This has largely taken the form of Corporate Social Responsibility (CSR). Whilst not a new topic, as CSR can trace its modern-day origins to the 1950's (Bowen, 1953), a recent development in the field of CSR has been an increased focus on SV. This focus has led to businesses across all industries being under increased scrutiny for how they create and deliver SV. It is argued the construction industry is under more pressure than most to deliver SV as it operates almost wholly in the public eye and so comes under more scrutiny and expectation (Watts et al., 2021).

One implication of this increased scrutiny and expectation is that those in management and leadership roles within the construction industry are required to not only engage with SV practices, but to then measure 
and communicate these practices in a manner that can be understood by the plethora of stakeholders involved. A failure to do so effectively could be the difference between procurement success or failure due to the increased weighting and focus SV criteria have in the procurement of construction works (Watts et al., 2019). However, this can prove problematic as SV is a subjective concept. With the diverse stakeholders involved, each potentially having their own SV interpretation, it can be problematic for a construction contractor to engage with, measure and communicate SV to the satisfaction of all stakeholders. In an effort to circumvent any potential problems that may arise because of this subjectivity, contractors could adopt objective measurement methods. Objectively measuring a subjective concept can be fraught with difficulties and wide-ranging ramifications such as nuanced and indirect SV implications being ignored or not being measured effectively. However, contractors are required to objectively measure many aspects of their existing business operations already (e.g. financial performance) and so this objective approach could therefore be adopted by contractors for all other measurement activities (such as social value). This approach is often referred to as 'the law of the instrument' or 'Maslow's hammer' after Abraham Maslow summarised that is tempting, to treat everything as a nail if the only tool you have is a hammer (Maslow, 1966).

The need for contractors to measure SV has been explored within the literature, with procurement success a main driver (see Watts et al, 2019). However, how this engagement occurs, why some measurement mechanisms are selected over others, and the ramifications of the decisions made by construction management and leadership pertaining to SV measurement and communication practices has not been extensively explored. The aim of this paper is to understand the ramifications of construction contractor SV measurement behaviour, as well as any contractor motivations and what the implications are for industry management and leadership. First, this paper outlines the size and importance of the construction industry and contextualises the research parameters. The paper then summarises a brief history of CSR and SV before the debates around the subjective and objective nature of SV are engaged with. Legitimacy theory is then introduced as the underlying theoretic lens through which the decisions of construction industry management and leadership professionals are viewed. The methodological position of the paper and research methods adopted are then outlined before the results are presented and discussed. Finally, the paper concludes with the implications the findings have for current and future construction industry practices and key lessons for the construction industry. This paper contributes to the social value and construction industry literature regarding the leadership and management of the industry pertaining to SV motivations, measurements, practices, and ramifications.

\section{THE CONSTRUCTION INDUSTRY}

The construction industry includes the design, construction, maintenance and demolition of built assets, engineering, and infrastructure works. Globally, it is estimated that aggregative investment until 2040 will exceed \$3.7 billion annually (Deloitte, 2019). In the United Kingdom (UK) construction contributes significantly to the economy, representing approximately $9 \%$ of economic output (BEIS, 2018). According to a UK Government briefing document in 2018 the construction industry contributed $£ 117$ billion to the UK economy, and is responsible for over 2.4 million jobs across 343,000 different businesses (Rhodes, 2019). It can therefore be concluded that the construction industry has a significant impact upon the UK economic output.

Within the UK construction industry, the public sector accounts for approximately $26 \%$ of construction work, with the private sector making up the rest. Historic economic data has shown that public sector workload remains fairly buoyant during times of economic uncertainty (Rhodes, 2015). This could help explain why contractors engage with the public sector despite the often-additional requirements imposed. Such requirements include those imposed by the SVA. These include the need for construction contractors to engage with, and then measure and communicate their SV activities. However, management's philanthropic values and succumbing to the pressures imposed by wider stakeholder expectations cannot be underestimated as drivers of social value behaviour. Nevertheless, the SVA plays a key role in imposing social value requirements upon contractors who engage with public sector work. The introduction of the 
SVA therefore ultimately placed an obligation on any company wanting to win public sector work to be able to effectively measure and communicate their social value (Watson et al., 2016). However, the SVA itself cannot claim to be the historic driving force of SV focused behaviours.

\section{A HISTORY OF SOCIAL VALUE}

Organisations acting as good corporate citizens is nothing new. There have been countless examples of organisational good behaviours, and some of these can be traced back hundreds of years (Carroll, 2015). It is argued that the modern-day incarnation of Corporate Social Responsibility (CSR) can be traced to the idea of wealthy industrialists giving back to society in tough economic times that was raised by Bowen (1953). Bowen's book, Social Responsibilities of the Businessman (1953) is credited with bringing to the forefront of modern business actions the age-old concept of general goodwill by those with the ability to make a positive difference. In the book it is wealthy business owners who are challenged to increase their social responsibility due to increasing post war prosperity (Bowen, 1953). The concept then grew throughout the 60's and 70's with the advent of social movements and the increased realisation that business behaviour could be shaped by stakeholder mobilisation (Carroll, 1999).

This journey then took CSR and wider business responsibility through an evolution of sorts from social responsibility to more environmentally focussed strategies. Perhaps fuel for those who link business intentions with only superficial action to illustrate their responsibility for work winning purposes, a decline of CSR activity was witnessed in the 1980's which has been linked to the economic issues of the time. However, in defence of business, it can be argued that without economic certainty a company may not be able to operate in the long term let alone commit resources to socially responsible actions where they are not directly linked to business operations.

The prosperous 1990's and early 2000's brought a return of CSR to the forefront of business activity, but with a continued evolution of understanding and expectation. As business wealth and stakeholder involvement and demands increased over the millennium and into the last decade the focus of organisational CSR expanded (or perhaps arguably went full circle) to include all manner of social, economic, and environmental factors that business may be directly or indirectly involved in, or may be completely separate but judged of such societal importance there is an expectation upon all businesses to play their part. Over the previous two decades despite times of economic turbulence CSR has remained a key business priority and an important stakeholder expectation.

However, the decline in CSR focus in the 80's during economically difficult times can perhaps add credibility to one of the more dominant CSR definitions proposed. The pyramid of CSR by Carroll (1991), in which it was argued that CSR is a philanthropic business priority only after economic, legal, and ethical targets have been achieved. Amongst the plethora of CSR definitions published over the years, the 'CSR pyramid' which was first proposed by Carroll in 1979, then further developed in 1991, has served a base for lots of CSR research with its wide-ranging encompassing approach to the subject. Carroll (1991) argues that a company's CSR journey starts with their economic responsibilities, then moves to their legal responsibilities, then ethical responsibilities before finally arriving (at the top of the pyramid) at philanthropic responsibility.

Carroll's approach to defining CSR could be argued to serve as an all-encompassing umbrella concept under which numerous interpretations and approaches exist (Barthorpe, 2010). A somewhat opposite approach to the one adopted by Carroll is to have a bespoke tailored definition of CSR that is specific to each stakeholder (Watts et al., 2019). However, the potential drawback to such an approach is the numerous measurement metrics and communications required for each and every stakeholder to reach an agreement over a shared understanding of CSR. Broadly, this paper describes CSR as the strategies and actions of organisations in how they maximise any positive impacts and minimise any negative impacts that arise from their business operations pertaining to their economic, social, and environmental actions.

Whilst arriving at an agreed definition of CSR (and SV) has proved problematic, the beneficial impacts experienced by all parties engaged with CSR, and specifically with SV, cannot be denied. Social Value has always been an important ingredient in the CSR mixture, but for many years was not focused upon as much 
as the arguably more easily quantifiable economic and environmental aspects of business responsibility. Nevertheless, the past decade has seen an increased focus upon SV elements. This is particularly illustrated with the introduction of the Public Services (Social Value) Act (2012) (SVA). This act, amongst other things, served to refocus and broaden the organisational practices that fall under the CSR banner onto more socially accountable criterion. However, whilst the benefits of CSR and SV practices to those intended recipients may be obvious, such as the creation of employment opportunities, organisations also receive a wealth of benefits for their CSR and SV actions. These can include an enhanced reputation amongst stakeholders, improving levels of customer satisfaction for those who feel they are transacting with an ethical and responsible business, and increased financial performance as a direct result of additional sales and cost efficiencies (Saeidi et al., 2015). There have also been studies that have revealed those organisations who embrace CSR and SV are increasingly perceived as legitimate.

\section{CORPORATE SOCIAL RESPONSIBILITY, SOCIAL VALUE AND LEGITIMACY THOERY}

Legitimacy theory is the idea that organisations behave in certain ways to purposefully gain legitimacy in the eyes of stakeholders (Watts and Higham, 2020). For instance, if an organisation was to engage in actions that meet the expectations of society, they would receive a social licence to operate through bestowed legitimacy (Bachmann and Ingenhoff, 2016). The theoretical lens of legitimacy theory provides a framework through which the engagement of such legitimacy seeking actions, and the resulting legitimacy experienced, can be viewed and understood. Duff (2017) extensively outlines the stages of legitimacy theory with three main categories: pragmatic legitimacy, moral legitimacy, and cognitive legitimacy. Each of these categories then has further sub-categories with organisations either seeking to achieve a certain type of legitimacy through their actions and strategies or seeking to treat the legitimacy categories as a continuum and progress from one to the next over time. Table 1 outline the main and sub-categories of legitimacy theory.

TABLE 1

LEGITIMACY THEORY CATEGORIES ADAPTED FROM DUFF (2017)

\section{Type of Legitimacy \\ Sub-Category}

Exchange - Organisations adopt practices in the

Pragmatic - Where practical consequences directly arise from organisational actions

Moral - Where stakeholders perceive organisations to be doing the 'right thing'

Cognitive - Where stakeholders perceive their own motivations reflect the organisation's hope they result in legitimacy

Influence - Stakeholders perceive that organisations have societal interests

Dispositional - Stakeholders perceive organisations have concern for society

Consequential - Stakeholders judge organisations on their achievements

Procedural - Organisations embrace socially accepted practices

Structural - Stakeholders believe an organisation structures itself to achieve advertised aims Personal - Stakeholders believe organisational management have high morals

Comprehensibility - Where an organisation purposefully structures itself for ease of stakeholder understanding Taken for granted - Stakeholders believe the organisation is one of the only ones who can meet their needs 
Previous studies have found that legitimacy theory can help explain organisational actions in regards to adopting CSR and SV focused behaviours (see O'Dwyer et al., 2011; Thorne et al., 2014; Duff, 2017). Watts and Higham (2020) found an indirect relationship also existed with SV and legitimacy in that the actions of public clients who utilised SV focused procurement criteria were also perceived as more legitimate for the SV practices then adopted by the main and sub-contractors. Legitimacy, therefore, can be described as an important benefit to organisations when they engage with CSR and SV and can help to explain the increasing participation of organisations in CSR and SV behaviours. A recent industrially focussed global business survey confirms that CSR is now embraced by the majority of large-scale organisations as a central part of their business identity (KPMG, 2017). Whilst the motivations of the companies involved were not explored in great detail, it can be argued that their increasing adoption of socially responsible practices, in the UK at least, can be in part attributed to legislation increasing socially focussed criterion in public sector procurement practices. One example of such legislation is The Public Services (Social Value) Act (2012). The SVA governs public body procurement behaviour by legitimising the use of criterion in procurement other than purely financial (Watts et al., 2019). The SVA allows public bodies to take additional social value achieved (as put forward by the tenderer) into consideration when awarding contracts so that the successful contractor is not necessarily the one who puts forward the lowest immediate cost (Loosemore, 2016). This, however, is where potential difficulties can arise in that the subjective concept of $\mathrm{SV}$ is required to be objectively communicated and compared.

\section{THE SUBJECTIVE AND OBJECTIVE APPROACHES TO MEASURING SOCIAL VALUE}

To successfully communicate SV, a shared understanding must be reached, at a minimum between the company and client, but also ideally between a wider cohort of stakeholders (Watts et al, 2019). However, with multiple stakeholders potentially each holding unique SV interpretations making reaching an agreement over a definition problematic, accurate measurement and clear communication is difficult to achieve (Loosemore and Higgon, 2016). The problem at the heart of the CSR and SV debates is arguably the attempts to effectively communicate with wider cohorts simultaneously, as the concepts ultimately mean different things to each party involved (Watts et al, 2019a). Approaches can largely be categorised as either subjective or objective. Subjective is where meanings are socially constructed and are therefore subject to change (Bryman, 2016). Subjective attempts to define CSR allow each stakeholder when faced with the same communication to arrive at their own interpretation (Griffith, 2011). However, one problem that exists with such subjectivity is that it is open to potential abuse by some companies who purposefully mask their failure to effectively engage with SV with ambiguous and opaque terminology (Watts et al., 2019).

Objective approaches are where a fact-based natural science method is adopted that implies a phenomenon has an existence independent of social actors (Robson and McCartan, 2017). The benefits to objective approaches include the ability for phenomena (in this case SV metrics) to be quantified and communicated in a method that a wide body of stakeholders can simultaneously understand. Whilst numerous different methods of measuring SV do exist (Wood and Leighton, 2010; Higham et al, 2018), many of those that are adopted by construction contractors objectively quantify SV so that benefits can be realised such as the ease of written communicated for inclusion in tender returns. Indeed, it has been argued that SV generally has objective requirements in its need to be measured, communicated and widely understood (Loosemore and Higgon, 2016). A perspective that has been largely perpetuated on the view that SV is achieved only by setting specific targets with result in a measurable financial return (Social Impact Investment Taskforce, 2014). However, although objective attempts to define CSR and SV are adopted by some parties, is several parties adopt their own objective, but different, measures, this may ultimately lead to competing and often conflicting definitions that serve to further exacerbate attempts to reach a consensus amongst stakeholders (Zhao et al., 2012).

Literature is dominated by an array of tools, metrics, frameworks and models that have been developed with the sole aim of predicting and measuring social value attainment. Proponents of these techniques such as Rees (2009) and Higham et al (2018) argue such evaluation frameworks provide fundamental building 
blocks for comprehensive change, by providing practical, transparent and simple to understand criteria to which the industry can respond in manageable steps, thereby empowering construction professionals to think about sustainability in an experiential way, with the safety net of expert guidance, checks and balances (Schweber, 2013). Yet Haapio and Viitaniemi (2008) and more recently Higham et al (2018) have questioned the validity of monetising sustainability, a theoretical construct far removed from the operation of the market mechanism. At the core of their objection is the assertion that monetary units are likely to limit the validity of any sustainability evaluation produced.

The most contentious issue in the adoption of such objective frameworks is the quantification and monetisation of intangible social outcomes using financial proxies (Arudson et al., 2013; Krley et al., 2013) which can lead analysts to take some extremely imaginative and adventurous pathways when appraising social return (Krley et al., 2013). It can also lead contractors to apply retrospective SV justifications to achieve client requirements (Russel, 2013). Yet it is this objective need to quantify such a subjective concept that perpetuates the tension at the heart of SV debates. These debates are dealt with however, as the benefits that SV can afford those who engage can be immense. From being the difference between procurement success and failure, (visible) engagement with SV can also afford a degree of legitimacy in the eyes of the wider stakeholder population (Watts et al., 2019). It is understanding this legitimacy, and the decisions made in an effort to gain and maintain any legitimacy that can help unlock understanding the motivations behind contractor SV decisions. Contractors need to measure and communicate the subjectivity of SV and arguably choose an objective, monetary derived method by which to do this. Although this decision in itself is presumed yet not explored in any great detail in the literature. The ramifications of this process are also not fully understood. This paper adopts the theoretical lens of legitimacy theory and seeks to explore how and why contractors engage with SV and understand any impact objectively measuring and communicating SV has on the concept's subjectivity.

\section{RESEARCH METHODOLOGY}

Ontology is questioning of the very nature of reality and is argued to consists of two dominant ontological positions; constructivism and objectivism (Bryman, 2016). Constructivism refers to a belief that meanings are socially constructed and agreed between relevant actors. Epistemologically, a constructivism approach is of an interpretivist position. This is where meanings are subjective and so ultimately are best expressed through qualitative data. As objectivism approach derives from fact-based natural sciences, and in the case of SV this approach is ultimately of a positivist epistemological position and is therefore best expressed through quantitative data. This arguably encompasses many of the current measurement tools currently used in the construction industry. As SV measurements and data are often difficult to quantify, they tend towards the adoption of a quantitative, and somewhat reductionist, approach.

The packaging of SV as quantitative data driven from an objectivist standpoint by many SV measurement tools adopted in the UK construction industry continues to dominate practice. This paper, however, subscribes to the argument that SV is best understood from a constructivist ontological viewpoint. Indeed, it is through this approach that the views, perceptions, actions, and motivations of construction contractors can be best understood (Cresswell, 2013). To maximise the amount of qualitative data gained, semi-structured interviews were selected as the appropriate research method due to their ability to explore participant understandings in great depth and allowed topics to be built upon with interesting avenues that arose during the course of the interview able to be pursued further (Bryman, 2016).

Fifteen semi-structured interviews were conducted with individuals involved in work winning each from a different UK construction contractor. These interviews were structured around the elements of legitimacy theory described in table 1 and acted as a framework for the interview questions asked. The websites of the top thirty construction contractors by turnover in 2019 and 2020 were viewed, and introductory emails sent to individuals identified online as being appropriate to the research. Initially, ten positive responses were received. This included three procurement and work winning directors, four bid managers and three senior estimators. Follow up emails were then sent to those with whom interviews had not been arranged at the initial research stage and a further five interviews were conducted. This consisted 
of two procurement and work winning management staff, two senior estimators and a bid manager. All interviews were conducted utilising telephone interviews which each lasted between 45 and 90 minutes. All interviews were recorded and then transcribed, and a process of narrative analysis conducted. Narrative analysis involves data in the form of stories. It is the process of summarising participant responses to reveal their deeper understandings without reducing responses to quantitative variables (Loosemore and Bridgeman, 2018). Such stories can be compared or even grouped together to reveal both similarities and differences of opinions and interpretations, and is increasingly popular as a social science analysis method (Griffin and May, 2012).

\section{FINDINGS AND DISCUSSION}

The research interviews and analysis of the qualitative data via a process of narrative analysis revealed several salient findings which have been grouped under the key areas of importance for construction industry management and leadership to be aware of so that business practices can be informed and developed.

\section{Contractors Are Increasingly Focused on Social Value}

The interview analysis revealed numerous consistencies existed between all contractors and the initial findings supported arguments in the literature. Firstly, reinforcing the increasing trends identified in the KPMG (2017) industrial survey all contractors interviewed agreed that they were all increasingly focussing on SV within their organisations, and this had been growing over recent years, with many only starting to report and consider their CSR and SV within the previous decade. All those interviewed also believed their respective organisations embraced CSR and SV as a core part of their business model. The introduction of the Public Services (Social Value) Act had also led to all contractors having an increasing focus and awareness of SV. However, all contractors also stipulated that even without the SVA in place during procurement they would still continue with their SV behaviours due to management values. Yet all contractors interviewed also won an element of their annual work from the public sector so this research could not determine the validity of this further. Although this area wasn't the focus of this paper, it was an interesting insight and one that is worth further exploration in future research.

\section{Social Value Measurement Tools Are Increasingly Used}

All contractors interviewed were involved with some form of SV measurement. Again, there was a consensus of all interviewee's in that SV measurement was utilised to support and enhance the communication of SV and the ability to 'hold SV activities to account' for their return on investment. Such findings supported those in the literature who argue that SV has objective requirements and needs to be measured and communicated (Loosemore and Higgon, 2016). However, differences in understandings were witnessed in each contractor's perceptions of SV measurement. Whilst each contractor discussed terms and practices that overlapped in places, they all had somewhat different perceptions of SV, that were driven in part from the needs and perceptions of their numerous clients. Ultimately, clients determined how contractors understood and interpreted SV. Contractors opinions it appears are influenced and warped by the mixture of their client's views, and so measurement tools were selected on the basis of them being able to provide a single method of communication that would encompass and resonate with as many of their clients as possible. An awareness of this influence is of paramount importance to the management and leadership of construction industry contractors as it can allow a concentration of resources to focus upon those SV initiatives that are of priority to the majority of clients. It can also allow new clients to be identified whose SV aims can be more easily achieved as they overlap with a contractor's current areas of focus.

\section{How SV Measurement Tools Serve to Contribute to Both the Subjective and Objective SV Arguments}

In total, seven different types of SV measurement tools were utilised by the fifteen contractors, with all but one using a recognised third-party measurement tool. This illustrates how there appears to be no single 
market leading SV measurement method. With each method communicating SV in a different way, this also arguably contributes to the difficulties and confusions that persist in reaching an agreed SV definition. Each measurement tool utilised offers an objective output to their calculations on SV (monetary metrics). All the measurement tools were of an objective and qualitative nature and so arguably reduced SV down to the figures used to express SV. Interestingly there was no consistency reported across the six different measurement tools, with each objective output differing (even when measuring the same SV initiative and behaviour). For instance, one contractor reported using two different social value measurement tools across their business operations and adopting a 'pick and mix' approach when it came time to compiling tenders for procurement, or even when reporting on progress to existing clients. The results of whichever tool had the highest monetary output were used, even if this meant using one tool to measure one practice, and a different tool to measure a different practice. The interviews explored this further and revealed the contractor saw no contradiction over the legitimacy of either SV measurement tool. It appears the tools were not questioned or rigorously explored, simply used and exploited for the benefits they brought. Due to the number of different SV measurement tools adopted, each with their own set of measurement metrics and different outputs when measuring the same activities, the tools also contribute to the subjectivity of the SV concept. The multiple objective approaches appear to further subjective debates.

\section{Maslow Was Right - Why Contractors Monetise Social Value}

Analysis of the interviews also revealed that eight of the contractors interviewed felt the SV measurement method they used fully measured and communicated SV. There was a consensus across these eight contractors that SV could be fully measured, and they saw no issues in the reduction of benefits to financial metrics - even when it was discussed how a reductionist approach to measurement could lose the nuanced benefits other SV practices offered. Many contractors, it appears, are of the opinion that if a SV practice can be measured, it is worth considering, if it cannot, then it is not. These eight were all of the opinion that SV was objective, and once agreed between stakeholders, could be easily measured and communicated using financial metrics. This is despite arguments in the literature that social value means different things to different people (Watts et al., 2019a) and that a lack of widely agreed definitions results in SV being difficult to measure and communicate (Loosemore and Higgon, 2016). The seven remaining contractors also all believed that SV was objective, and that despite different stakeholder understandings and perceptions, agreements could be reached as to what SV is, and then measurement proxies should be used. When this was explored further it was revealed that contractors have copious previous experience with measurement and reporting, but of financial performance. They therefore have the internal infrastructure and methods of working to capture and formulate data for organisational use. The data received and required for SV has fallen into these existing manners of working with one contractor reporting it is the exact same employees utilising slightly different software and tools to produce the data they require, whether SV or regarding traditional financial outputs. It appears that Maslow's observations are apt, in that if the only tool you have is a hammer, you will treat everything as a nail.

However, four contractors felt that the majority of SV could be captured in some form of financial metrics but admitted there were elements of SV that arose from the practices they undertook which could not be accurately captured in monetary terms - but other metrics could be used - the tools to measure such SV just were not available yet. These four contractors believed such SV was impossible to accurately capture at present and so made no effort to do so. Only one contractor interviewed believed there was a need to measure SV using both financial and non-financial metrics, and they were currently considering how best to do this but had no solution at the time of interviewing. All contractors, therefore, only participated in SV practices they were able to accurately measure, and that resulted in a set of financial variables that could be easily communicated to numerous stakeholders. Any SV practices that couldn't be easily measured using currently adopted measurement tools were likely to be ignored or marginalised, with focus shown to SV practices that easily leant themselves to financial measurement, further supporting the cognitive bias of Maslow's hammer. This is of key importance to construction industry leadership as there needs to be an increased awareness, that even if the SV proposed contributed to successful project 
procurement, it may fall short of the benefits that could be realised if alternative SV practices were adopted, albeit ones the benefits of which were harder to measure and communicate.

\section{Legitimacy Is a Key Driver in a Contractors' Social Value Based Decisions}

Utilising the theoretical lens of legitimacy helped reveal further contractor motivations for the SV measurement behaviours. Contractors ultimately sought cognitive legitimacy from clients, and so therefore tried to purposefully structure their operations to reflect those of the client (comprehensibility) and also position themselves as the single contractor who can adequately fulfil the clients every need, including their need for SV measurement (taken for granted). Whilst contractors did argue that they would engage in some form of SV activity regardless of client intent, their actions described in their responses revealed a clear structuring of their behaviours towards being perceived as legitimate in the eyes of clients.

This was echoed in the reported behaviours of ultimately trying to get clients to understand they [contractors] were trying to appear ethical actors in society by doing what was viewed as the 'right thing' (moral legitimacy). Whilst it should be stressed all contractors did repeat their desire to engage with SV outside of client requirements, there was a clear pattern visible that client needs and demands drove SV behaviour and served to focus a contractor behaviours in to not only engaging with SV, but to appear to be engaging with SV to all clients. Such behaviours resonate with both structural legitimacy and procedural legitimacy in that social practices are overtly adopted with actions undertaken in a direct effort to influence the perceptions of others. Construction management therefore need to be aware that embracing SV practices alone is perhaps not enough to compete with fellow contractors. It is what each contractor is perceived to be involved in, with regards to SV activity, that helps improve their legitimacy in the eyes of clients, and not necessarily their SV actions alone.

\section{CONCLUSION}

Construction contractors engage with Social Value measurement in order to be able to communicate their SV practices and results to stakeholders such as public sector clients, as this will increase the likelihood of successful procurement. However, the subjectivity of SV does not easily lend itself to measurement. Nevertheless, contractors are increasingly adopting measurement tools that take an objective approach and reduce SV to monetary figures. Through interviews with fifteen UK construction contractors, this paper reveals that the majority of contractors interviewed see SV only as that which can be measured with financial metrics. This is in part due to current and previous practices in organisational data collection and communication, and also the ease of which objective data can be communicated to clients. It seems if the only tool you have is a hammer, you will treat everything as a nail. Whilst some contractors do see the subjective nature of SV posing a problem for measurement in that every aspect cannot be easily measured with financial metrics, at present amongst the vast majority of contractors no effort is being made to measure these practices. In fact, the SV practices that do not result in easy to measure and communicate financial metrics are being largely ignored. Legitimacy theory offers an explanation for the motivations behind such practices, in that contractors position themselves when measuring and reporting on SV in a manner they believe will be perceived as legitimate in the eyes of clients. The findings of this paper reveal that SV practices which result in a higher amount of SV generated are potentially being ignored for practices which are easier to measure and communicate. Such findings contribute to understanding the ramifications of contractor decisions to measure and communicate SV in objective terms. In practice this may mean public sector clients need to consider the procurement requirements they are imposing on contractors in order to achieve the highest amount of SV possible, and not just that which can be easily condensed to financial terms. The findings of this paper contribute to the increasing SV awareness construction leadership and management need to be aware of. The problems associated with objective SV measurement tools, and the motivations and behaviours of fellow contractors, that are pursued in part, because it is behaviours they have always adopted, and are doing so even when faced with different challenges, such as the subjective nature of SV. Further research could be conducted around understanding what other drivers are behind contractor reporting practices, and also further research could be aimed at establishing how SV practices 
that do not lend themselves to be financial metrics can be effectively measured and communicated. How and why clients perceive contractors as legitimate, and the wider benefits such legitimacy affords are also areas that should be pursued further to contribute to the findings of this paper.

\section{REFERENCES}

Arudson, M., Lyon, F., McKay, S., \& Moro, D. (2013). Valuing Social Value? The Nature and Controversies of Measuring Social Return on Investment. Voluntary Sector Review, 4(1), 3-18.

Bachmann, P., \& Ingenhoff, D. (2016). Legitimacy through CSR disclosures? The advantage outweighs the disadvantages. Public Relations Review, 42, 386-394.

Barthorpe, S. (2010). Implementing corporate social responsibility in the UK construction industry. Property Management, 28(1), 4-17.

BEIS. (2018). Industrial Strategy - Construction Sector Deal. Retrieved from https:/assets.publishing.service.gov.uk/government/uploads/system/uploads/attachment_data/file/ 731871/construction-sector-deal-print-single.pdf

Bowen, H. (1953). Social Responsibilities of the businessman. New York: Harper \& Row.

Bryman, A. (2016). Social Research Methods (5th Ed.). Oxford University Press, Oxford.

Carroll, A. (1999). CSR: Evolution of a definitional construct. Business \& Society, 38, 268-295.

Carroll, A. (2015). Corporate Social Responsibility: The centrepiece of competing and complementary frameworks. Organisational Dynamics, 44, 87-96.

Carroll, A.B. (1991). The Pyramid of Corporate Social Responsibility: Toward the Moral Management of Organizational Stakeholders. Business Horizons, 4, 39-48.

Cresswell, J. (2013). Research Design: Qualitative, quantitative, and mixed methods approaches. Sage. London.

Deloitte. (2019). Global Power of Construction 2018. Retrieved from https://www2.deloitte.com/us/en/pages/energy-and-resources/articles/global-constructionindustry-overview.html

Griffin, A., \& May, V. (2012). Narrative analysis and interpretative phenomenological analysis. In C. Seale, Researching Society and Culture (3rd Ed.). Sage Publications. London.

Griffith, A. (2011). Fulfilling Contractors' Corporate Social Responsibilities using Standards-Based Management Systems. International Journal of Construction Management, 11(2), 37-47.

Haapio, A., \& Viitaniemi, P. (2008). A critical review of building environmental assessment tools. Environmental Impact Assessment Review, 28(7), 469-482.

Higham, A.P., Barlow, C., Bichard, E., \& Richards, A. (2018). Valuing Sustainable change in the Built Environment: Using SuROI to appraise built environment projects. Journal of Facilities Management, 16(3), 315-355.

KPMG. (2017). The Road Ahead; The KPMG Survey of Corporate Responsibility Reporting 2017. KPMG Global Sustainability Services 2017.

Krley, G., Münscher, R., \& Mülbert, K. (2013). Social Return on Investment (SROI): State-of-the-art perspectives. Heidelberg: Universtat Heidelberg.

Loosemore, M., \& Bridgeman, J. (2018). The social impact of construction industry schools-based corporate volunteering. Construction Management and Economics, 36(5), 243-258.

Loosemore, M., \& Higgon D. (2016). Social Enterprise in the Construction Industry. Routledge, Oxon.

Maslow, A. (1966). The Psychology of Science: A Reconnaissance. Harper \& Row. University of Wisconsin.

Rees, W. (2009). The ecological crisis and self delusion: Implications for the building sector. Building Research and Information, 37(3), 300-311.

Rhodes, C. (2015). Construction Industry: Statistics and policy (Nr 01432). House of Commons Library. Retrieved from www.parliament.uk/briefing-papers/sn01432.pdf

Rhodes, C. (2019). Construction Industry: Statistics and policy (Nr 01432). House of Commons Library. Retrieved from https://commonslibrary.parliament.uk/research-briefings/sn01432/ 
Robson, C., \& McCartan, K. (2017). Real World Research (4th Edition). John Wiley and Sons. London. Russel, S. (2013). Journey to Impact: A Practitioner Perspective on Measuring Social Impact. Midland Heart.

Saeidi, S., Sofian, S., Saeidi, P., Saeidi, S.P., \& Saaeidi, S. (2014). How does corporate social responsibility contribute to firm financial performance? The mediating role of competitive advantage, reputation, and customer satisfaction. Journal of Business Research.

Schweber, L. (2013). The effect of BREEAM on clients and construction professionals. Building Research and Information, 41(2), 129-145.

Social Impact Investment Taskforce. (2014). Impact investment: The invisible heart of markets [Online]. Retrieved from http://www.socialimpactinvestment.org/reports/Impact\%20Investment\%20Report\%20FINAL [3].pdf

Thorne, L., Mahoney, L., \& Manetti, G. (2014). Motivations for Issuing standalone CSR reports: A survey of Canadian firms. Accounting, Auditing \& Accountability Journal, 27(4), 686-714.

Watson, K.J., Evans, J., Karvonen, A., \& Whitley, T. (2016). Capturing the social value of buildings: The promise of Social Return on Investment (SROI). Building and Environment, 103, 289-301.

Watts, G., Ferne, S., \& Dainty. A. (2019a). Measuring Social Value in Construction. In ARCOM 2019 (35th Annual Conference). 2nd-4th September 2019, Leeds Beckett University

Watts, G., Fernie, S., \& Dainty, A. (2019). Paradox and legitimacy in construction: How CSR reports restrict CSR practice. International Journal of Building Pathology and Adaptation, 37(2), 231246.

Wood, C., \& Leighton, D. (2010). Measuring social value: The gap between theory and practice. Retrieved from https://www.demos.co.uk/files/Measuring_social_value_-_web.pdf

Xue, J., Shen, G., Yang, R., Wu, H., Li, X., \& Lin, X. (2020). Mapping the knowledge domain of stakeholder perspective studies in construction projects: A bibliometric approach. International Journal of Project Management, 38, 313-326.

Zhao, Z., Zhao, X., Davidson, K., \& Zou, J. (2012). A corporate social responsibility indicator system for construction enterprises. Journal of Cleaner Production, 29-30, 277-289. 